The Egyptian Journal of Hospital Medicine (July 2019) Vol. 76 (2), Page 3454-3459

\title{
Role of Laparoscopy in Management of Non-Palpable Undescended Testis in Children
}

\author{
Mohamed M. AbdElsalam, Khalid M. Elshimy, Akram M. Elbatarny, Mahmoud A. Elafifi \\ Pediatric Surgery Department. Faculty of Medicine. Tanta University \\ Corresponding author: Mohamed M. AbdElsalam, email: dr_medo_mas_4040@yahoo.com
}

\begin{abstract}
Background: Several techniques have been described for treatment of intra-abdominal testis including microsurgical autotransplantation, primary laparoscopic orchiopexy (VILO), one- and two-stage laparoscopic Fowler-Stephens procedures, and staged laparoscopic traction orchiopexy (Shehata technique).

Aim of the work: To evaluate the role of laparoscopy in the treatment of non-palpable undescended testis.

Patients and methods: This study was carried out in the Pediatric Surgery Unit, Tanta University Hospitals, during the period from April 2017 to October 2018, on 37 cryptorchid boys with 40 non-palpable testes. The mean age of the patients was $3.46 \pm$ SD 3.1 years. Laparoscopic exploration was done for all cases, and if testes were found intraabdominally, with rough measurement of the length oftesticular vessels (TV), decision was taken either to do VILO or Shehata technique.

Results: Out of 40 testes, 17 testes (42.5\%) were vanishing, 3 intra-abdominal testes $(7.5 \%)$ with long TV enough to undergo VILO, and 20 intra-abdominal testes (50\%) with short testicular vessels underwent Shehata technique. Follow up for 3 -12 months postoperatively showed that all 3 testes underwent VILO were normal in size and vascularity. While the 20 testes underwentShehata technique, 19/20 (95\%) testes were normal in size, while small testis was detected in $1 / 20$ testis $(5 \%)$.

Conclusion: VILO has excellent results in management ofintra-abdominal testes with sufficient TV length while Shehata technique has excellent results in management ofintra-abdominal testis with short TV.

Keywords: laparoscopy, intra abdominalt estis, primary laparoscopic orchiopexy, Fowler-Stephens procedures, Shehata technique.
\end{abstract}

\section{INTRODUCTION}

Cryptorchidism or undescended testis (UDT) is one of the most common genital anomalies in childhood. Itsincidence is $3-5 \%$ in full term newborn, and affect more than one third of premature newborn. The incidence decrease to $1 \%$ at age of 3 months. About $20 \%$ of UDT are impalpable, and about $50 \%$ of these impalpable testes are either vanished or atrophic ${ }^{[1-3]}$.

Many diagnostic methods have been used for the evaluation and management of the undescended testis, including imaging studies and multiple surgical procedures. Laparoscopy has become the most common way to identify the position of intra-abdominal testis and exclusion of vanished testes ${ }^{[4]}$.

Surgical management of UDT is performed to preserve testicular function (spermatogenesis) and to prevent the potential complications of undescended testis ${ }^{[1]}$.

Regarding the optimal age of orchiopexy many recent findings suggest that early intervention $(6-12 \mathrm{~ms}$ of age) is most beneficial. Other findings suggest that there is high rate of spontaneous descent during the first 3 months of life, so observation of undescendedtestes is advocated till 3 months of age, if the testis remains nonpalpable at 3 months of age, it is unlikely to become palpable by waiting another 3 months. Therefore, diagnostic laparoscopy and orchidopexy could be performed from 3 months of age ${ }^{[2]}$.

Intra-abdominal testes have been traditionally divided into low-lying (within $2 \mathrm{~cm}$ from IIR) and highlying (over $2 \mathrm{~cm}$ from IIR). For the low-lying testes, one- stage laparoscopicorchidopexy has been practiced and achieving good results. On the other hand, the high-lying testis is more controversial as regards the ideal management protocol. Fowler-Stephens staged laparoscopic orchidopexy has dominated the surgical techniques for decades but with only suboptimal results. Alternatively, testicular microvascularauto transplantation is tedious, time consuming and requires special experience and equipment making it less feasible and far from becoming a worldwide standard ${ }^{[5,6]}$.

Traction to achieve organ growth or stretch has been a charming surgical concept employed by general surgeons to lengthen esophagus after resections. Kimura and Foker described two different techniques depending on traction to lengthen the esophagus in treatment of pure long gab esophageal atresia ${ }^{[9]}$. Keetley and Torek in 1909 have separately proposed techniques to lengthen the short spermatic vessels for abdominal testes based on traction by fixation to the thigh. However, those techniques and many others were quickly abandoned after achieving disappointing results losing many testes probably because of the sudden and uncontrolled tension on the testicular vessels ${ }^{[7]}$. In 2008Shehata reintroduced the concept of traction in the management of high intraabdominal testes. In his landmark paper, he proposed a new staged laparoscopic-assisted technique for bringing down the abdominal testis with minimal complications while maintaining their viability ${ }^{[8]}$.

The aim of this study was to evaluate the role of laparoscopy in the treatment of non-palpable 
undescended testis in pediatric age group as regard feasibility, safety, fate of testis and complications.

\section{PATIENTS AND METHODS}

This study was carried out in Pediatric Surgery Unit, Tanta University Hospitals during the period from April 2017 to October 2018, on 37 cryptorchid boys with 40 non palpable testes.

The study was approved by ethical committee of faculty of medicine, Tanta University (approval code 534 /04/2017).

Patient's parents received an explanation to the purpose of the study, idea of the operation, instructions and side effects of these technique and a written informed consent to participate in the study was taken. The study included infants and children with diagnosed unilateral or bilateral non-palpable undescended testis with an age ranged from 6 months to 12 years. Patients withdisorders of sexual development (DSDS) were excluded from our study. All patients were subjected to full clinical examination and laboratory investigations as required. Inguinoscrotal ultrasound was done for all cases to detect the site of the non-palpable testis if visualized.

\section{Operative technique:}

All patients received general anesthesia with endotracheal intubation with injection of IV broad spectrum antibiotic with induction of anesthesia. Examination under general anesthesia was done for all patients to confirm non-palpable testis. Patients were placed in the supine position with the surgeon stood at the head of the table and patient, with the anesthesia machine moved to the right side of the operating table, the camera man to the left side of the surgeon, the scrub nurse to the left of the table and the monitor at the feet of the patient. Local infiltration anesthesia was administered at the sites of port insertion using a mixture of lignocaine $2 \%(4 \mathrm{mg} / \mathrm{kg})$ and bupivacaine $0.5 \%$ $(2 \mathrm{mg} / \mathrm{kg})$.

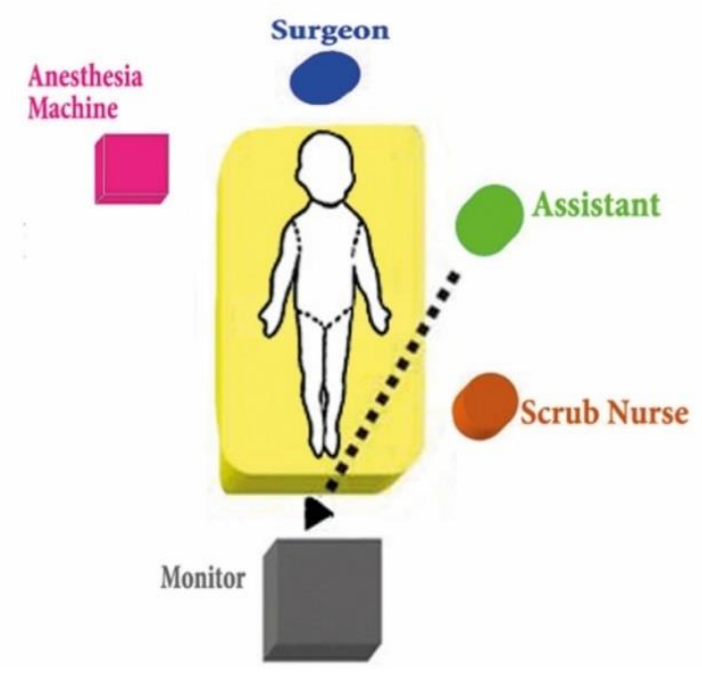

Figure (1): Position of the surgeon and assistant surgeon.

In all patients, a 5-mm port was inserted at the umbilicus for the telescope. This trocar was mainly inserted using the open technique to establish pneumoperitoneum.The abdomen was insufflated with $\mathrm{CO}_{2}$ initially at $6-8 \mathrm{mmHg}$ pressure, with a flow of $1.5 \mathrm{~L} / \mathrm{min}$. The pressure could then be raised to 8 $12 \mathrm{mmHg}$ and the flow to $2-3 \mathrm{~L} / \mathrm{min}$ according to age. $\mathrm{A} 30^{\circ}(5 \mathrm{~mm})$ telescope was introduced through the umbilical port.The patient position was modified to the Trendelenburg's position with the ipsilateral side up to move the bowel out of the way with the arms tucked to the side of the patient.Laparoscopy was used firstly to inspect peritoneal cavity and examine the inguinal region to assess site and size of the testis.

\section{This exploration usually resulted in one of two alternative findings :}

1-Both the vas and vessels are passing through the IIR. Then laparoscopic exploration is terminated and a conventional open inguinal canal exploration was performed. Those were excluded from our study.

2-Both vas and vessels meeting intra-abdominally:

1- Blind-ending or very thin leash vessels were considered the end-point of exploration.

2-If otherwise both the vas and vessels terminated in a visible testis at variable distance from (IIR).

- Two instruments 5-mm were inserted under vision at anterior axillary line near the level of the umbilicus.

- A low-power monopolar hook diathermy was used to dissect and divide the gubernaculum carefully in layers to avoid injuring a looping vas if present.

The testis is taken to the contralateral IIR and left there as a rough measurement of $T V$ length:

1) If it stayed there, then its vas and vessels had sufficient length amenable for one-stage laparoscopic-assisted orchidopexy (VILO). Those were fixed in the scrotum in the same stage.

2) If it recoiled back, we started freeing the testis by dissection of the lateral peritoneum using scissors and/or low-power cutting monopolar hook diathermy.

-The testis was then taken again to the contralateral IIR, if it still recoiled back, then its vas and vessels were short enough mandating preliminary traction to lengthen the testicular vessels, $1^{\text {st }}$ stage (T1).

-Then the testis was fixed to the anterior abdominal wall, one inch above and medial to contra lateralanterior superior iliac spine(ASIS). 2/0 non absorbable suture (Ethibond or silk)on a round needle was passed through the abdominal wall after making a small $2 \mathrm{~mm}$ incision with an 11 blade, received inside the abdomen under laparoscopic vision by a 5-mm needle holder, then the suture was passed through the testis and returned 
ejhm.journals.ekb.eg

through the abdominal wall at the same incision either with a back through with the needle holder or brought out by a retrieval needle suture to be tied outside provided that the testis was subjected to minimal tension inside the abdominal cavity. This traction knot was buried under the skin and the wound was closed with steristreps.

\section{$2^{\text {nd }}$ stage (T2):}

A second stage laparoscopic-assisted orchiopexy was planned after 12 weeks. The preoperative preparation, positioning and trocar positions were the same like the first stage. The abdominal cavity was inspected for:

1-Any adhesive bands.

2- Slippage of the suture and retraction of the testis.

3- Internal herniation, and position of the intestine in relation to the TV were noted and recorded.

Then, the fixation stitchwas divided and any adhesions were lysed and the testis was tested for the descent to the bottom of the scrotum by resting the testis at the contralateralIIR:

A) If long, testis would be fixed in subdartos pouch, position was reported.

B) If short, redo traction wasdone. And the patient was left for another 12 weeks.

Postoperative care was the same as the first stage.

Follow up visits were planned at one week, one month, and 3 months postoperatively.

a) Clinical examination for testicular position (inguinal, high scrotal, or low scrotal).

b) Ultrasonography, and color Doppler examination after 3 months from the second stage, to check for testicular size and vascularity(if feasible) to be compared with the other testis in unilateral UDT cases.

\section{Statistical analysis}

Data were fed to the computer and analyzed using IBM SPSS software package version 20.0. (Armonk, NY: IBM Corp). Qualitative data were described using number and percent. Quantitative data were described using range (minimum and maximum), mean, standard deviation and median. Significance of the obtained results was judged at the $5 \%$ level.

\section{RESULTS}

This study included 37 cryptorchid boys with 40 non palpable testes. Their ages ranged from 9 months to 11 years (mean $3.46 \pm \mathrm{SD} 3.1$ years). Three cases $(17.7 \%)$, were bilateral, 15 cases $(35.3 \%)$ were left intraabdominal testes, and 19 cases (47\%) were right intraabdominal testes.

Preoperativeultrasonographic examination was able to detect the testis intra-abdominally in only 15testes (37.5\%), and the remaining 25 testes $(62.5 \%)$ were not visualized by ultrasound. Out of 25 nonvisualized testes, 17 testes were vanished during laparoscopic exploration and 8 testes were found intraabdominally with US accuracy $80 \%$.

In this study, 17 testes were vanished, 3 underwent one stage vessel intact laparoscopic orchiopexy, and 20 testes underwent staged laparoscopic traction orchiopexy, and all were done laparoscopically without conversion to open technique. Operative time was calculated from skin incision to skin closure (Table 1) No intraoperative complications were noted in $1^{\text {st }}$ and $2^{\text {nd }}$ stages including bleeding, orinjury to vas, vessels, or bowel.

Table (1): Operative time for VILO and staged traction (T1, T2):

\begin{tabular}{|c|c|c|c|c|}
\hline Column1 & NO & $\begin{array}{l}\text { Min. - } \\
\text { Max. }\end{array}$ & $\begin{array}{l}\text { Mean } \pm \\
\text { SD. }\end{array}$ & Median \\
\hline VILO & 3 & $25-35$ & $29.33 \pm 5.13$ & 28 \\
\hline $\begin{array}{l}\text { Staged } \\
\text { traction } \\
\text { orchiopexy } \\
\text { Unilateral } \\
\text { cases (T1): }\end{array}$ & 14 & $30-41$ & \begin{tabular}{|l|}
$35.14 \pm$ \\
3.59
\end{tabular} & 35 \\
\hline $\begin{array}{l}\text { Bilateral } \\
\text { cases (T1): }\end{array}$ & 3 & $45-55$ & $49.66 \pm 5.0$ & 49 \\
\hline $\begin{array}{l}\text { Unilateral } \\
\text { cases (T2): }\end{array}$ & 14 & $45-57$ & $\begin{array}{l}50.21 \pm \\
4.07\end{array}$ & 49.5 \\
\hline $\begin{array}{l}\text { Bilateral } \\
\text { cases (T2): }\end{array}$ & 3 & $53-65$ & $\begin{array}{l}59.33 \pm \\
6.02\end{array}$ & 60 \\
\hline
\end{tabular}

For cases underwent (Shehata technique), during $2^{\text {nd }}$ stage, adhesions occurred between the bowel and the cord, and between the bowel and the denuded original site of the testis in $6 / 20$ testes $(30 \%)$, and were lysed easily.Adhesions between both cords in bilateral cases occurred in 1 of 3 bilateral cases (33.3\%), and could be lysed with caution with no complications. Excessive adhesions between the fixed testis and the abdominal wall occurred in $2 / 20$ testes (10\%). In these cases a patch of peritoneum was cut along with the testis.Slipped testis occurred in 1/20 testis (unilateral case) (5\%) with no need for redo traction as the length of testicular vessels was enough to do $2^{\text {nd }}$ stage orchiopexy.

Follow up for $3-12$ months postoperatively clinically and by Doppler ultrasound showed thatall 3 testes underwent VILO were normal in size and vascularity, two testes were in a low testicular position and one testis was in a high testicular position. 
Table (2): Descriptive analysis of the studied cases underwent Shehata technique according to testicular position, consistency, viability, and size by US.

\begin{tabular}{|c|c|c|c|c|c|}
\hline & \multicolumn{2}{|l|}{ No } & \multicolumn{2}{|l|}{$\%$} \\
\hline & & Shehata technique & VILO & Shehata technique & VILO \\
\hline \multirow{3}{*}{$\begin{array}{l}\text { Testicular } \\
\text { position: }\end{array}$} & Low scrotal & 16 & 2 & 80 & 66.7 \\
\hline & High scrotal & 4 & 1 & 20 & 33.3 \\
\hline & Pre scrotal & $\mathbf{0}$ & $\mathbf{0}$ & $\mathbf{0}$ & $\mathbf{0}$ \\
\hline \multirow{2}{*}{$\begin{array}{l}\text { Testicular } \\
\text { consistency: }\end{array}$} & Firm & 18 & 2 & 90 & 66.7 \\
\hline & Soft & 2 & 1 & 10 & 33.3 \\
\hline \multirow{2}{*}{$\begin{array}{l}\text { Testicular } \\
\text { viability: }\end{array}$} & Viable & 20 & 3 & 100 & 100 \\
\hline & Non viable & $\mathbf{0}$ & $\mathbf{0}$ & $\mathbf{0}$ & $\mathbf{0}$ \\
\hline \multirow{2}{*}{ Testicular size: } & Normal testis & 19 & 3 & 95 & 100 \\
\hline & small testis & 1 & $\mathbf{0}$ & 5 & $\mathbf{0}$ \\
\hline
\end{tabular}

\section{DISCUSSION}

In our study, boys were aged 9 months -11 years (mean $3.46 \pm 3.1$ years) on admission, 17 testes( 17 cases) were vanished, 3 testes (3 cases) underwent one stage VILO were managed before the age of 2 years, 20 testes ( 17 cases) underwent Shehata technique, $10 / 17$ cases $(58.8 \%)$ were managed before the age of 2 years, and $6 / 17$ cases $(35.3 \%)$ were managed at the age of 2-6 years, and one case (5.9) was delayed to be managed after the age of 6 years. Shehata in 2008 reported that age of patients ranged from 1 year to 5 years with a mean of 2.3 years, 6/10 cases $(60 \%)$ were managed before the age of 2 years, and $4 / 10$ cases $(40 \%)$ were delayed to be managed after the age of 2 years ${ }^{[8]}$.

In 2016 he and his colleagues continued their research and reported that the age of patients ranged from 6 months to 9 years with a mean of 3.2 years, $69 / 140$ cases $(49.3 \%)$ were managed before the age of 2 years, and $52 / 140$ cases $(37.1 \%)$ were managed at the age of $2-6$ years, $19 / 140$ cases $(13.6 \%)$ were managed after the age of 6 years ${ }^{[5]}$.

In this study, correlation between ultrasound findings and laparoscopic finding was done. If we consider the whole managed 37 cases with 40 non palpable testes, only $15 / 40$ testes (37.5\%) werevisualized intra-abdominally, and the remaining $25 / 40$ testes $(62.5 \%)$ were not visualized by the ultrasound. Seventeen 17/25 of non visualized testes were vanishing while $8 / 25$ were found intraabdominally. The accuracy of ultrasound was $80 \%$. Pawetet al. in 2017, also correlated between ultrasound findings and laparoscopic or surgical exploration for impalpable testes. The US study was done for 65 non-palpable testes and was able to detect the testis in 27 of the 42 testes on which orchiopexy or orchiectomy was performed (sensitivity of US was $64 \%)$.
If we consider the whole managed 65 nonpalpable testes, the accuracy of ultrasound for all cases was $77 \%{ }^{[11]}$.

For cases underwent Shehata technique, we had only one slipped testis although this patient was subjected to the $2^{\text {nd }}$ stage after 12 weeks. Shehatain 2008 had one slipped testis out of 10 testes $(10 \%)$ although the traction period in his study was only 2 weeks. This means that slippage is not directly related to only traction time ${ }^{[8]}$.

In 2016, they reported that during the $2^{\text {nd }}$ stage $16 / 140$ testes (11\%) showed slippage of the fixing stitch $^{[5]}$.Elsherbenyet al. in 2018, reported that during the 2nd stage $2 / 22$ testes $(9.1 \%)$ showed slippage of the fixing stitch ${ }^{[10]}$.

In our study, there was no postoperative complications after VILO, for cases underwent Shehata technique there was no postoperative complications after the $1^{\text {st }}$ stage specifically no internal hernia behind TV or adhesive intestinal obstruction, but only 3 cases in which stitch sinus occurred at the site of traction suture, and were managed conservatively until the knot was removed in the $2^{\text {nd }}$ stage. Shehata et al in 2016, reported that the traction period passed smoothly without occurrence of adhesive intestinal obstruction or internal herniation behind TV, since the bowel is usually found overlying and not incarcerated behind the stretched vessels on laparoscopic exploration at the $2^{\text {nd }}$ stage ${ }^{[5]}$.

For cases underwent Shehata technique,adhesions between both cords in bilateral cases occurred in 1 of 3 bilateral cases $(33.3 \%)$, and could be lysed with caution with no complications. With direct personal communication with prof. Shehata suggested that to avoid adhesions between both cords, bilateral cases could be done in 3 stages where in the $1^{\text {st }}$ stage one testis is tracted, $2^{\text {nd }}$ stage this testis is brought down and the other testis is tracted, 
then in the $3^{\text {rd }}$ stage it is brought down. Elsherbenyet al. in 2018, reported occurrence of adhesion between both cords occurred in one patient with bilateral intraabdominal testes. The adhesions were lysed, and orchiopexy was done successfully ${ }^{[10]}$.

In our study, testicular tissue elongation was found in 4 case underwent Shehata technique. This observation was not mentioned in other similar studies. The size and consistency of these cases were normal at operation and follow up and we did not know if this finding had any implications.

In our study, all testes could be brought to intra or low scrotal position during the $2^{\text {nd }}$ stage of Shehata technique or VILO. Deepak et al. in 2018, reported using staged LFS technique for 35 intra-abdominal testes. During $2^{\text {nd }}$ stage, intra scrotal fixation was done for $31 / 35$ testes $(88.6 \%$ ), while supra scrotal fixation was done for $3 / 35$ testes $(8.6 \%)$, and the remaining testis $(2.8 \%)$ was atrophic and excision was done during $2^{\text {nd }}$ stage ${ }^{[12]}$.

In our study as regard to position of testes after VILO, 2 testes $(66.7 \%)$ were in a low scrotal position, and one testis $(33.3 \%)$ was in a high scrotal position.After the $2^{\text {nd }}$ stage of Shehata technique, 16 testes $(80 \%)$ were in a low testicular position, 4 testes $(20 \%)$ were in a high testicular position, and no testes were detected in pre scrotal position. Shehata et al.,in 2008 , reported that 3 testes $(33.3 \%)$ were low scrotal, 4 testes $(44.5 \%)$ were mid scrotal, and 2 testes $(22.2 \%)$ were high scrotal ${ }^{[8]}$.

In their 2016 report, they used scrotal position as a parameter of measuring success rate ${ }^{[5]}$.Lintula et al,in 2008, reported that for 19 testicular units undergoing laparoscopic orchiopexy (SSLO in 17 testes and LFSO in 2 testes), 12 testes (66\%) were low scrotal, 4 testes $(22 \%)$ were mid scrotal, 1 testis $(6 \%)$ was high scrotal, 1 testis $(6 \%)$ was vanished, and one patient was lost to follow up ${ }^{[13]}$.

During this work follow up ultrasonography was done for all cases 3 months after VILO and showed that all 3 testes were viable with normal size. After the $2^{\text {nd }}$ stage of Shehata technique U showed that all 20 testes were viable. As regards testicular size by ultrasound, it was reported normal compared to the contralateral testis in 19 (95\%) while one testis $(5 \%)$ was smaller in size than the contralateral testis but no frank atrophy, this was noted in the 11 years old case.Shehataetal.in 2016, defined the success as scrotal testis (low or mid scrotal) with normal size (within $75-100 \%$ of the other side) with good vascularity by Doppler, and reported that success rate was related to age of boys at time of the operation. Success rate in patients aged less than 2 years was $90.3 \%$, and success decreased to $83 \%$ in patients aged from 2-6 years, and for patients older than 6 years success rate was $62.5 \%$, with overall success for staged laparoscopic traction orchiopexy was $84 \%^{[6]}$. This is consistent with our results as the only case who presented with a small sized testis was an 11 years old boy. Elsherbeny et al. in 2018, reported that all testes managed by the 2 stages of staged laparoscopic traction orchiopexy were normal, and none of the participants developed testicular atrophy ${ }^{[10]}$.

Mahziyaret al. in 2016 performed LFSO in 24 patients. Two testis were complicatedat the $2^{\text {nd }}$ postoperative day of the $2^{\text {nd }}$ stage and the patients developed scrotal pain and signs of testicular ischemia that were confirmed by Doppler ultrasound. Orchidectomy was done for the 2 testes. Follow up ultrasound $1-3$ months after the $2^{\text {nd }}$ stage showed atrophy in another 2 testes. Surgery success rate for the study was $83.3 \%{ }^{[3]}$.Deepak et al., in 2018, defined the success as intra scrotal testis with good testicular vascularity, and reported that success rate for staged LFS was $68.6 \%{ }^{[12]}$ Alirezaet al.in 2016, performed LFSO for 35 testes, 4 testes $(11.4 \%)$ were found to be atrophic on follow-up. Also performed SSLO for 50 testes, 4 testes $(8 \%)$ were found to be atrophic on follow-up ${ }^{[6]}$.

The gradual elongation of the testicular vessels over the course of 12 weeks traction period is the reason of success of the traction technique. This is in contrast to excessive abrupt tension in previous techniques that may have lead to higher atrophy rates. The probable cause of testicular vascular pedicle elongation is stretching by the weight of the intestine and the regular movement of the abdominal wall during respiration. The preservation of TV may be a contributing factor to keeping the viability of the tracted testis and the relatively smaller percentage of testicular atrophy compared to F S orchiopexy ${ }^{[5]}$.

Briefly VILO has excellent results in management of intraabdominal testes with sufficient TV length while staged laparoscopic traction orchiopexy (shehata technique) has excellent results in management of intraabdominal testis with short TV. Further histological studies are required to evaluate the long term effect on fertility.

\section{REFERENCES}

1.Vikraman J, John M.Hutson, Ruili Li et al.(2016): The undescended testis: Clinical management and scientific advances. Seminars in Pediatric Surgery, 25 : 241-248.

2.Sepúlveda $X$. and LópezEgaña $\mathbf{P}(2016)$ :Current management of non-palpable testes: a literature review and clinical results. TranslPediatr.,5(4):233-239.

3.Mahziyar $\mathrm{K}$, Dinyar $\mathrm{K}$, Hayat $\mathrm{M}$ et al.(2016) : Laparoscopic Two Stage Fowler-Stephens Orchiopexy: A Single Center Experience. Persian j. med. sci. , 3: 137-141. 
4.El-Anany F, Gad El-Moula M, Abdel Moneim A et al .(2007): Laparoscopy for impalpable testis: classification based management. SurgEndosc., 21: 449-454.

5.Shehata S , Shalaby $R$, Ismail M et al. (2016) : Staged Laparoscopic Traction-Orchiopexy for Intra-abdominal Testis (Shehata Technique). Journal of Pediatric Surgery, 51 211-215.

6.Alireza A, Joan C. D, Ruben B et al. (2016) : Staged Fowler-Stephens and Single-Staged Laparoscopic Orchiopexy for Intra-Abdominal Testes: is There a Difference? a Single Institution Experience. j.urology, 9 : 6069.

7.Shehata S , Shehata S M. andFahmy M (2013) : The intra-abdominal testis: lessons from the past, and ideas for the future. PediatrSurgInt., 29:1039-1045.

8.Shehata S (2008) :Laparoscopically assisted gradual controlled traction on the testicular vessels: a new concept in the management of abdominal testis. Eur J PediatrSurg., 18:402-406.
9.Carroll $M$ and Arnold G (2013) : Congenital anomalies of the esophagus, pediatric surgery, Arnold G Coran ,7th edition, EL SEVIER.

10.ElsherbenyM ,Abdallah, Abouzeid A et al. (2018) : Staged laparoscopic traction orchiopexy for intra-abdominal testis: is it always feasible?. Journal of Pediatric Urology, 11: 01.021.

11.Paweł O, Tomasz Ż, Błażej R et al. (2017) : Treatment of impalpable testis - one clinic's experience. Video surgery Miniinv.,12 (2): 166-171.

12.Deepak B, ashish $P$, shabnam $B$ et al .(2018) : evaluation of two staged fowler- Stephen laparoscopic orchiopexy for intraabdominal testes.pediatrSurgInt., 34, 97- 103.

13.LintulaH, Hannu K, Matti E et al. (2008) : Laparoscopic Versus Open Orchidopexy in Children with Intra-abdominal Testes. journal of laparoendoscopic\& advanced surgical techniques, 18: 3 . 